\title{
The use of affective interaction design in car user interfaces
}

\author{
Dimitrios Gkouskos ${ }^{\mathrm{a},{ }^{*}}$ and Fang Chen ${ }^{\mathrm{b}}$ \\ ${ }^{\mathrm{a}, \mathrm{b},}$,Department of Interaction Design, Chalmers University of Technology, Gothenburg, Sweden
}

\begin{abstract}
Recent developments in the car industry have put Human Machine Interfaces under the spotlight. Developing gratifying human-car interactions has become one of the more prominent areas that car manufacturers want to invest in. However, concepts like emotional design remain foreign to the industry. In this study 12 experts on the field of automobile HMI design were interviewed in order to investigate their needs and opinions of emotional design. Results show that emotional design has yet to be introduced for this context of use. Designers need a tool customized for the intricacies of the car HMI field that can provide them with support and guidance so that they can create emotionally attractive experiences for drivers and passengers alike.
\end{abstract}

Keywords: Emotional Design, Affective, Interaction, Design, Pleasurable, Interface

\section{Introduction}

Advancements in psychology show that emotions are an integral part of rational thinking and decision making [20], [13]. According to Epstein, there are two modes of information processing in humans, the experiential mode and the rational mode. Of the two, the experiential mode is driven by emotions and it provides more rapid processing and decision making than the rational mode [13]. With this knowledge, the necessity to consider emotions is evident in order to create pleasurable experiences for the user. In order for any product to be successful, it is necessary for its design team to move past usability and view the interaction between user and product holistically, including the emotional aspects, a process also known as emotional or affective interaction design. This is true for all types of products and services, including human machine interaction in vehicles.

In other fields, emotional design has greatly affected the way products are created. There are concrete examples from the field of web design [19], the mobile phone industry [9] with the iPhone being a clear case [12], the hotel industry [11], in smart homes [23], and others. While usability brought users to the center of the designer's attention, emotional design has provided a better scope for understanding user needs. Products are not only bought in order to complete the tasks they were created for, but also to satisfy the user's emotional desires.

\section{Related Work}

Two of the most prominent frameworks in the field of emotional design are those of Don Norman and Patrick Jordan. They are not competing, but rather complement each other in understanding the emotional implications in product-user interaction. Norman proposes three levels in which design affects the user, the visceral, the behavioral and the reflective level [22], whereas Jordan proposes four different distinct types of pleasure; physio-pleasure, sociopleasure, psycho-pleasure and ideo-pleasure [18]. The visceral level is comprised of experiences that come directly from the five senses. Norman states, "The principles underlying visceral design are wired in, consistent across people and cultures"'[21]. Examples of these principles are symmetry, bright, primary colors, harmonic sounds etc. The behavioral level involves the usability aspect of a product or service. The four components of good behavioral design are

*Corresponding author. E-mail: dimitrios.gkouskos@chalmers.se, Tel: +46704079142 
function, understandability, usability and physical feel as stated in Norman's book "The Design Of Everyday Things" [21]. The reflective level incorporates the meaning of a product to a specific person as well as the effect that the product has on said user's selfimage. It is important to note that Norman states that of the three levels, good reflective design is what makes a lasting impact to the user, whereas good visceral design has a short term effect on the user's opinion [22].

There are four distinct types of pleasure, proposed by anthropologist Lionel Tiger [25], and then adapted by Patrick Jordan [18]. Physio-pleasure has to do with pleasure that comes from the five senses. This form of pleasure stems from good visceral design. Socio-pleasure is "the enjoyment derived from relationships with others". This type of pleasure comes from a combination of behavioral and reflective design. Psycho-pleasure is closely related to people's emotional and cognitive reactions. Good behavioral design can invoke this type of pleasure. Ideo-pleasure originates from reflective design. This type of pleasure is achieved when products fulfill users' needs for certain ideologies, beliefs and values.

While both of these theories provide a concise overview of emotional design issues, they do not offer any specific methods for applying and evaluating emotional design. Other major contributions are those of Desmet et al., who have identified different product emotions [7], and have created a non-verbal method of assessing emotions elicited by products named pr-Emo [9], [10]. Desmet and Hekkert have also proposed a framework of product experience [8] that identifies different types of emotions related to interactions with products. Similar work has been done by Bradley et al. with the development of the self-assessment manikin tool or SAM [5]. The SAM tool measures three distinct variables, namely pleasure, arousal and dominance. These represent the user's emotional response when experiencing or interacting with a product. The SAM has been widely applied with positive results in different studies [3, 16, 17]. However, in the field of Automotive User Interface Design, there is a severe lack of literature regarding affective issues of design, with Gomez being one of the few researchers that we found in this context. In his research, Gomez used a variety of selfreport and physiological measurement tools and showed that previous emotional states and circumstances have an effect on the user's appraisal of the driving experience $[14,15]$. With the absence of research methods for affective design for automotive user interfaces, we turned to current practitioners of
Human Machine Interface design in order to investigate how they cope with these issues.

\section{Purpose}

The purpose of this study is to investigate whether affective design theories have influenced the development process of vehicle Human Machine interfaces, and if so, provide an overview of their practice in the field. A secondary goal is to identify the most pressing challenges that HMI designers face when they attempt to create emotionally attractive interactions in order to create solutions for these issues in the future.

\section{Method}

The study consists of a set of semi-structured interviews, followed by a thematic analysis of the interview data. A set of questions was designed in order to guide the course of the interviews. Since the type of interview that was carried out was semi-structured, the questions were not presented to the interviewees as-is but they were used as a general guide in order to steer the discussion towards the topic at hand. These questions tackled the following themes that correspond to the purpose of the study: The participants' previous experience and background, emotional design knowledge and its effects on the design process, the participants' current work process and design goals, challenges the participants face regarding emotional design, and their opinion of an ideal emotional design support tool. There was also a category named 'other' which included comments that were deemed interesting but did not fit any of the pre-defined topics mentioned above. Each interview lasted about 30 minutes. The audio from the interviews was digitally recorded. A thematic analysis [2, 4] was performed on the collected audio data, and the participants' answers were analyzed according to the themes mentioned above. The results of the analysis were categorized according to the pre-selected topics addressed by the interview questions. For each category, relevant quotes were transcribed. The findings section below includes the most popular opinions and important quotes from each category.

\subsection{Participants}

The interviewees were twelve industry experts between 28 and 50 years old, from three different major 
companies. All of the experts are currently working in the Swedish automotive industry, on different aspects of Human Machine Interface development, from product planning and requirements specification, to prototyping, interaction design and evaluation. Each expert had a minimum of 5 years of experience in the field. With combined experience of over 60 years the interviewees provide a comprehensive overview of common practices in this industry at least as far as Scandinavian car manufacturers are concerned. Most of the experts have worked for many companies including major car manufacturers in Sweden, mobile phone manufacturers, and suppliers of in-vehicle technology.

\section{Findings}

\subsection{Emotional design and its effects on the design process}

When asked, "what do you know about emotional and pleasurable design?" most participants stated that they know it is a very important aspect of the design process. One participant said that emotional design is "the main reason when choosing a product... we use a lot of things not because of function but because they make us feel positive emotion". Another participant stated that "...all successful products that give a successful user experience talk to our emotions". Most participants mentioned that they are aware of theories such as those of Norman and Jordan; however, they do not actively practice emotional design since they do not know how to apply this knowledge to their HMI design tasks. The experts stated that they have no specific tools for creating emotionally attractive products and no way to evaluate the results of their efforts. Many keep in mind that the experience they create should be pleasurable, but without a methodical approach, this requirement becomes an afterthought. Finally, a few experts believe that emotional design is mostly related to branding and the visceral level of design. In a discussion regarding the impact of emotional design, most of the professionals referred to the user satisfaction surveys that accompany usability tests that these experts conduct. The surveys usually have the form of a Likert scale questionnaire, and along with expert knowledge and personal preference, they have the biggest influence on the assessment of the emotional aspects of a product.

\subsection{Work process and design goals}

During the questions regarding the experts' work processes many of the participants mentioned that for every new project they make most decisions based on their personal experience. Information that is relevant to a project is collected from different groups within a company, and then this knowledge is used in order to make decisions regarding the best way to design a certain interaction or function. There is some use of personas and some discussion about the emotional aspects of the final product, but there are no distinct steps taken in order to build a pleasurable experience. More specifically, there are certain design goals that can be related to emotional design, however it is unclear whether these goals have been achieved since there is no specific way to review and evaluate the results of the design process. Functional requirements and buzzwords are the driving forces behind most decisions regarding design. One participant characterized the design goals he is given as "emotional attributes that are subjective...with no clear instructions [on how to implement them]".

\subsection{Challenges}

When participants were asked about challenges that they might face when attempting to design emotionally attractive products, all of them mentioned that the biggest issue is the lack of guidance regarding this aspect of design. Moreover they stated that the automotive industry evolves at a slower pace than other fields that seem more prone to adopt new methodologies, such as the computer industry and the mobile phone industry. Safety, and implementing new technology have high priority while creating emotionally pleasing experiences comes second. One interviewee mentioned that requirements might come from the need to implement new technology rather than the need to create a positive user experience. Another participant said, "We should start with the design and then add technology...now we have technology first." Since cars are complex, there are many actors with different perspectives that influence design decisions, and each of these choices can have great effects on the engineering, the ergonomics and the cost of a vehicle. The lack of specified design and evaluation resources hinders the collaboration of these actors since they are left to rely on personal opinions and previous experience. This issue is magnified by the complexity of each automobile, which does 
not allow for a smaller team -with potentially better teamwork- to oversee a project.

\subsection{A support tool for emotional design}

All of the participants expressed that they would find an emotional design support tool very useful during the interviews. When asked to describe their ideal tool, the most common requirements were to have a tool that provides support throughout the design process, from the conception of a project until the final iterations, as well as on all levels, from detailed components to the car as a whole. A method that can guide all the participants in a project towards creating an emotionally pleasing experience was seen as a requirement. Furthermore, all of the experts would welcome multimedia information such as photos, sketch boards and video clips as an additional way to communicate ideas that can result to a pleasurable design. Finally, the ability to evaluate the emotional attractiveness of different concepts is seen as vital by the majority of the participants. Therefore they believe that an iterative way to review and redesign different concepts is desirable, if not necessary.

\section{Limitations}

The findings presented in this paper originate from data that was collected from a small group of professionals that work in Swedish HMI companies. Therefore it would be a stretch to claim that the answers collected can be generalized to a greater population. Moreover there is always the possibility that the participants did not answer truthfully or that they had strong personal biases that influenced their responses. For the improvement of the external validity of this study, more groups of professionals from different countries need to be interviewed. Given that this study is a first step towards developing a framework for the affective design of automotive user interfaces we believe that the results are valuable and are giving us a clear direction for future work.

\section{Discussion}

Our findings indicate that there are three main issues regarding emotional design in vehicle HMI's. First, we have the lack of collaboration and understanding between actors even when they work on the same HMI module, mainly due to the fact that many of them have an engineering approach to a design issue. The second issue is the misconception that emotional and pleasurable design only relates to branding and appearance. Finally there is the need to evaluate and assess design in terms of emotional attractiveness. In the past, there has been some research regarding the emotional and pleasurable aspects of design in cars $[1,6,24]$, however, the interview data shows that this knowledge has yet to be adopted. All of these issues point to the emergent necessity for emotional design tools that can support HMI professionals in implementing emotional design principles into their work process. These tools must be flexible, iterative, and applicable to all levels of a project from the complete vehicle (e.g. the overall feeling of the car, be it sporty, family oriented or made for business) to detailed components of it (e.g. display of ventilation settings at the center stack), and throughout the development process. Evaluation tools must be included as well, as it is evidently important to assess concepts and designs against the desired goals of the design team. The design of such a resource is a challenging task and will be the objective of future work. We believe that the identification of the emotional needs for different user types and the discovery of salient HMI properties for each of those types will provide the core knowledge that is needed for the development of such a resource.

\section{Conclusion}

While user satisfaction surveys can assist with the improvement of a product, they are insufficient since they do not enable the deep understanding of the user's needs that is required for the creation of emotionally attractive interactions. Furthermore, although experienced, experts cannot know the user needs unless they observe and ask actual users. The automotive HMI field needs to be introduced to the concept of emotional design and especially the behavioral and reflective parts of it. There is a clear necessity for tools and methods that are customized for this industry's context of use. Specialized tools can guide HMI designers and provide common ground and common goals so that design teams can better collaborate in order to create pleasurable interactions for the end user. We believe that a support framework for emotional design should consist of tools for identifying user needs with the use of methods like laddering, workshops, interviews and observations, as well as evaluation tools that can be both self-assessment 
based such as the SAM tool, and physiology based such as heart beat and skin temperature measurements. It falls on the research community to define the exact details of these tools and methods so that they best fit the needs of Human Interface design professionals.

\section{Acknowledgments}

We would like to thank Dr. Sus Lundgren for her invaluable help and support, as well as the people in the EFESOS project and at the IT department of Chalmers University for making this possible.

\section{References}

[1] Abbott, M. Engineering emotional product identities in highluxury vehicles. In Proceedings of the 5th. International Conference on Design and Emotion. (Gothenburg, Sweden, 2006).

[2] Aronson, J. A pragmatic view of thematic analysis. The qualitative report, 2, 1, (1994), 1-3.

[3] Backs, R. W., Silva, S. P. and Han, K. A comparison of younger and older adults' self-assessment manikin ratings of affective pictures. Experimental aging research, 31, 4, (2005), 421-440.

[4] Boyatzis, R. E. Transforming qualitative information: Thematic analysis and code development. Sage Publications, Inc, 1998.

[5] Bradley, M. M. and Lang, P. J. Measuring emotion: the selfassessment manikin and the semantic differential. Journal of behavior therapy and experimental psychiatry, 25, 1, (1994), 49-59.

[6] Bullinger, H., Bauer, W., Dangelmaier, M. and Widlroither, P. Analysing emotional impacts on acceptance of the HMI inside cars. City, 2001

[7] Desmet, D. A Basic Typology of Product Emotions. City, 2004.

[8] Desmet, P. and Hekkert, P. Framework of product experience. International Journal of Design, 1, 1, (2007), 57-66.

[9] Desmet, P., Overbeeke, K. and Tax, S. Designing Products with Added Emotional Value: Development and Appllcation of an Approach for Research Through Design. The Design Journal, 4, 1, (2001), 32-47.
[10] Desmet, P. M. A., Hekkert, P. and Jacobs, J. J. When a car makes you smile: Development and application of an instrument to measure product emotions. Advances in consumer research, 27(2000), 111-117.

[11] DubE, L., Le Bel, J. and Sears, D. From Customer Value to Engineering Pleasurable Experiences. Cornell Hotel and Restaurant Administration Quarterly, 40, 4, (2003).

[12] Ebner, M., Stickel, C. and Kolbitsch, J. iPhone/iPad human interface design. HCI in Work and Learning, Life and Leisure(2010), 489-492.

[13] Epstein, S. Integration of the cognitive and the psychodynamic unconscious. American Psychologist, 49(1994), 709-709.

[14] Gomez, R. E., Popovic, V. and Bucolo, S. Driving : the emotional experience and automotive design. In Proceedings of the Fourth International Conference on Design and Emotion (2004).

[15] Gomez, R. E., Popovic, V. and Bucolo, S. Emotional driving experiences. Design and Emotion Moves(2008), 141-164.

[16] Grimm, M. and Kroschel, K. Evaluation of natural emotions using self assessment manikins. IEEE, City, 2005.

[17] Hillman, C. H., Rosengren, K. S. and Smith, D. P. Emotion and motivated behavior: postural adjustments to affective picture viewing. Biological Psychology, 66, 1, (2004), 51-62.

[18] Jordan, P. W. Designing pleasurable products: An introduction to the new human factors. CRC, 2002.

[19] Kim, J., Lee, J. and Choi, D. Designing emotionally evocative homepages: an empirical study of the quantitative relations between design factors and emotional dimensions. International Journal of Human-Computer Studies, 59, 6 , (2003), 899-940.

[20] Loewenstein, G. and Lerner, J. S. The role of affect in decision making. Handbook of affective sciences(2003), 6-42.

[21] Norman, D. A. The design of everyday things. Basic Books New York, 2002.

[22] Norman, D. A. Emotional design: Why we love (or hate) everyday things. Basic Civitas Books, 2004.

[23] Such, M. J., Barber, R., Poveda, R., Belda-Lois, J. M., Gomez, A., Lopez, A., Cort, J. M. and Sanchez, M. The use of Emotional Design Techniques in user oriented design of interfaces within a smart house environment: Case study. Technology and Disability, 18, 4, (2006), 201-206.

[24] Sudarshan, P. K. and Ray, A. Joy of use in automotive touch screen UI for the driver. In Proceedings of the Second International Conference on Automotive User Interfaces and Interactive Vehicular Applications (Pittsburgh, Pennsylvania, USA, 2010).

[25] Tiger, L. The pursuit of pleasure. Transaction Pub, New Brunswick, New Jersey, 2000. 